\title{
Investigation of standardized administration of anti-platelet drugs and its effect on the prognosis of patients with coronary heart disease
}

\author{
CHAO DING $^{1 *}$, JIANHUA ZHANG $^{2 *}$, RONGCHENG LI $^{1}$, JIACAI WANG $^{1}$, \\ YONGCANG HU ${ }^{1}$, YANYAN CHEN ${ }^{1}$, XIANNAN $\mathrm{LI}^{1}$ and YAN XU ${ }^{3}$ \\ ${ }^{1}$ Department of Cardiology, Lu'an Shili Hospital of Anhui, Lu'an, Anhui 237006; ${ }^{2}$ Department of Cardiology, \\ The First Affiliated Hospital of Jinan University, Guangzhou, Guangdong 510630; ${ }^{3}$ Department of Cardiology, \\ The First Affiliated Hospital of Anhui Medical University, Hefei, Anhui 230022, P.R. China
}

Received September 17, 2015; Accepted October 20, 2016

DOI: $10.3892 /$ etm.2017.4903

\begin{abstract}
The aim of the present study was to explore the effect of adherence to standardized administration of anti-platelet drugs on the prognosis of patients with coronary heart disease. A total of 144 patients newly diagnosed with coronary heart disease at Lu'an Shili Hospital of Anhui Province (Lu'an, China) between June 2010 and June 2012 were followed up. Kaplan-Meier curves and the Cox regression model were used to evaluate the effects of standardized administration of anti-platelet drugs on primary and secondary end-point events. Of the patients with coronary heart disease, 109 (76\%) patients took standard anti-platelet drugs following discharge. Kaplan-Meier curve and Cox regression analysis showed that standardized administration of anti-platelet drugs reduced the risk of primary end-point events (including all-cause mortality, non-lethal myocardial infarction and stroke) of patients with coronary heart disease [hazard ratio $(\mathrm{HR})=0.307 ; 95 \%$ confidence interval $(\mathrm{CI})$ : 0.099-0.953; $\mathrm{P}=0.041)$ and all-cause mortality $(\mathrm{HR}=0.162 ; 95 \% \mathrm{CI}: 0.029-0.890 ; \mathrm{P}=0.036)$; however, standardized administration had no predictive value with regard to secondary end-point events. Standardized administration of anti-platelet drugs obviously reduced the risk of primary end-point events in patients with coronary heart disease, and further analysis showed that only all-cause mortality exhibited a statistically significant reduction.
\end{abstract}

Correspondence to: Dr Yan Xu, Department of Cardiology, The First Affiliated Hospital of Anhui Medical University, 218 Jixi Road, Shushan, Hefei, Anhui 230022, P.R. China

E-mail: yanxucn@126.com

*Contributed equally

Key words: coronary heart disease, anti-platelet therapy, percutaneous coronary intervention, primary end-points, all-cause mortality

\section{Introduction}

Coronary heart disease severely threatens the health of individuals worldwide. While it was the seventh-most frequent cause of mortality in China in 1990, it became the second-most frequent cause in 2010 (1). The main pathophysiological mechanism is the reduction of myocardial flow and insufficient oxygen supply of myocardial cells caused by coronary artery stenosis, leading to a series of hypoxic ischemic symptoms (2). Aggravation of atherosclerosis as well as cracking or even rupture of local plaques leads to platelet aggregation to result in an increase in blood viscosity, which causes a sudden reduction of coronary blood flow and induce acute myocardial infarction. As activation and aggregation of platelets is the cause of coronary heart disease (3), it is treated by standardized administration of anti-platelet drugs to reduce the risk of further coronary heart disease-associated events.

Percutaneous coronary intervention (PCI) is a common therapy for coronary heart disease. Stent thrombosis (ST) is one of the most severe complications after PCI. Compared with a bare metal stent, a drug-eluting stent obviously reduces the occurrence rate of in-stent restenosis after PCI but increases the risk of ST. Drug-eluting stents also delay vascular endothelial healing. Incomplete endothelialization and local vascular hypersensitivity may cause late ST, which increases patient mortality by $15-45 \%(4,5)$. Thus, anti-platelet therapy should be enhanced in patients with coronary heart disease after PCI, particularly after implantation of a drug-eluting stent. Studies have indicated that dual anti-platelet therapy comprising clopidogrel combined with aspirin after PCI significantly reduced the incidence rate of major adverse cardiac events $(6,7)$. The CURE trial confirmed that compared with aspirin treatment alone, long-term combined therapy with clopidogrel and aspirin significantly reduced the risk of cardiac events in patients presenting with acute coronary syndrome (ACS) after PCI (8). Furthermore, the CREDO trail showed that patients treated with aspirin and clopidogrel for up to 1 year had a significantly lower rate of cardiac events than those without dual anti-platelet therapy within 1 year (9). 
Anti-platelet therapy has an important role in the primary and secondary prevention of cardiovascular diseases and reduces the incidence of cardiac events, which is also a therapeutic basis of vascular diseases (10). Although relevant guidelines have emphasized the important role of anti-platelet therapy in coronary heart disease and recommended the standardized management to all physicians, certain patients with coronary heart disease do not adhere to their prescribed regimens for various reasons. The RESOLUTE China Registry Research (11) registered 1,800 patients with coronary heart disease who were implanted with the resolute zotarolimus-eluting stent at 30 centers in China and analysis suggested that adherence to dual anti-platelet therapy was $94 \%$ at 1 year. However, it is difficult to achieve this high proportion of adherence in clinical practice. The present study analyzed the standardized management of anti-platelet therapy in patients with coronary heart disease at Lu'an Shili Hospital of Anhui Province (Lu'an, China) and its impact on patient prognosis and the risk of end-point events through a prospective follow-up study.

\section{Materials and methods}

Subjects. A total of 144 patients newly diagnosed with coronary heart disease at Lu'an Shili Hospital of Anhui Province (Lu'an, China) between June 2010 and June 2012 were enrolled in the present study. The cohort comprised 59 females and 85 males, 56 patients with stable angina pectoris and 88 patients with acute coronary syndrome. The present study was performed in accordance with the declaration of Helsinki and approved by the Ethics Committee of Lu'an Shili Hospital (Lu'an, China). Written informed consent was obtained from all participants. Patients who suffered from peripheral vascular disease, thrombotic disease, severe liver and renal dysfunction, thyroid disease, cancer as well as infectious or autoimmune diseases were excluded. Patients who had received surgery $<3$ months previously, those receiving anti-inflammatory drugs or hormone replacement therapy as well as those with severe peptic ulcers, inflammation and hemorrhage were also excluded.

Follow-up. For each of the outpatients, self-administration of drugs was analyzed and follow-up was performed every three months. For this purpose, follow-up tables were designed and telephone interviews were performed by two professional cardiologists with sufficient knowledge regarding the diagnosis and prevention of coronary heart disease and who had been trained in a specific seminar. One further professional cardiologist monitored the follow-up process.

Definition of standardized administration. According to guidelines (12), patients were administered anti-platelet drugs as follows: Patients who had stable angina pectoris required continuous oral aspirin, and patients with ACS after PCI (drug-eluting stent implantation) required dual antiplatelet therapy with coadministration of aspirin and clopidogrel, for at least one year, followed by continuous oral aspirin. Continous oral administration of statins, beta-receptor antagonist and angiotensin-converting-enzyme inhibitor (ACEI)/angiotensin receptor blocker $(A R B)$ is required.
Clinical end-points. Primary end-points, also called major adverse cardiac events, included all-cause mortality, non-lethal myocardial infarction and stroke. Diagnostic evidence of myocardial infarction included clinical symptoms, electrocardiogram and myocardial enzyme, while that of stroke included clinical symptoms and computed tomography. Secondary end-points included grade-IV heart failure according to the New York Heart Association classification (13), hospitalized therapy and revascularization (PCI or coronary artery bypass graft surgery).

Statistical analysis. Statistical analysis was performed using SPSS13.0 software (SPSS, Inc., Chicago, IL, USA). Values are expressed as the mean \pm standard deviation. Student's $t$-test was used to analyze differences in continuous variables between two groups, and the chi-square test was used for classified variables. Furthermore, patients were divided into a standardized and a non-standardized administration group, according to administration of anti-platelet drugs standardly or not, and Kaplan-Meier curves were drawn to compare the incidence of end-point events between the two groups. The COX proportional hazards model was used for multiple factor analysis, providing the hazard ratio (HR) value and 95\% confidence interval (CI) in order to determine the risk of end-point events in patients with coronary heart disease treated with standardized therapy.

\section{Results}

Comparison of general data. A total of 114 patients with coronary heart disease were enrolled in the present study and the median follow-up time was 360 days. The standardized administration group contained 109 patients (76\%) and the non-standardized administration group contained 35 (24\%). A total of 70 patients with PCI treatment were included in the present study, and 56 patients $(80 \%)$ took standard administration of anti-platelet therapy. Table I shows that the non-standardized administration group contained a high proportion of smokers $(\mathrm{P}=0.020)$, while there were no significant differences between the two group regarding the other indexes, including age, gender, hypertension, diabetes, cardiovascular conditions, multiplicity of diseased vessels, side of main lesion or PCI therapy. However, the proportion of patients taking oral statins, beta receptor antagonists and ACEI/ARB was higher in standardized administration group compared to that in the non-standardized group $(\mathrm{P}<0.01)$.

Comparison of end-points between the two groups. Table II shows that the incidence rate of primary end-point events in the standardized administration group was significantly lower than that in the non-standardized administration group (6 vs. 17\%; $P=0.030$ ). Single event analysis showed that the incidence rate of non-lethal myocardial infarction and stroke was not significantly different, but that the incidence rate of all-cause mortality was significantly lower in the standardized administration group compared to that in the non-standardized administration group ( 2 vs. $11 \%$; $\mathrm{P}=0.013$ ). In addition, there was no statistical difference in the incidence rate of secondary end-point events between the two groups (Table II). 
Table I. Comparisons of indexes between two groups.

\begin{tabular}{|c|c|c|c|}
\hline Index & $\begin{array}{c}\text { Standardized OA-P } \\
\text { administration group }(\mathrm{n}=109)\end{array}$ & $\begin{array}{l}\text { Non-standardized OA-P } \\
\text { administration group }(n=35)\end{array}$ & P-value \\
\hline Mean age (years) & $63 \pm 9$ & $63 \pm 9$ & 0.320 \\
\hline Male gender, n (\%) & $65(60)$ & $20(57)$ & 0.794 \\
\hline Smoking, n (\%) & $9(8)$ & $8(23)$ & 0.020 \\
\hline Hypertension, n (\%) & $62(57)$ & $17(49)$ & 0.390 \\
\hline Diabetes, n (\%) & $10(9)$ & $3(9)$ & 0.914 \\
\hline Groups, n (\%) & & & 0.206 \\
\hline Stable angina pectoris & $38(35)$ & $18(51)$ & \\
\hline Unstable angina pectoris & $45(41)$ & $10(29)$ & \\
\hline Acute myocardial infarction & $26(24)$ & $7(20)$ & \\
\hline Multiplicity of vessels diseased, n (\%) & & & 0.401 \\
\hline One & $48(44)$ & $20(57)$ & \\
\hline Two & $33(30)$ & $8(23)$ & \\
\hline Three & $28(26)$ & $7(20)$ & \\
\hline Left main lesion, $\mathrm{n}(\%)$ & $7(6)$ & $3(9)$ & 0.663 \\
\hline PCI therapy, n (\%) & & & 0.241 \\
\hline Yes & $56(80)$ & $14(20)$ & \\
\hline No & $53(72)$ & $21(28)$ & \\
\hline \multicolumn{4}{|l|}{ Drug treatments, $\mathrm{n}(\%)$} \\
\hline Standardized oral statins & $99(91)$ & $8(23)$ & $<0.001$ \\
\hline Standardized oral $\beta$-receptor antagonist & $78(72)$ & $5(14)$ & $<0.001$ \\
\hline Standardized oral ACEI/ARB & $87(80)$ & $8(23)$ & $<0.001$ \\
\hline
\end{tabular}

O-AP, oral anti-platelet; PCI, percutaneous coronary intervention; ACEI, angiotensin-converting-enzyme inhibitor; ARB, angiotensin receptor blocker.

Table II. Comparison of the occurrence of primary and secondary end-point events between the two groups.

\begin{tabular}{lccc}
\hline Events & $\begin{array}{c}\text { Standardized OA-P } \\
\text { administration group (n=109) }\end{array}$ & $\begin{array}{c}\text { Non-standardized O-AP } \\
\text { administration group (n=35) }\end{array}$ & P-value \\
\hline $\begin{array}{l}\text { Primary end-point events, } \mathrm{n}(\%) \\
\text { Total }\end{array}$ & $6(6)$ & $6(17)$ & 0.030 \\
All-cause mortality & $2(2)$ & $4(11)$ & 0.013 \\
Non-lethal stroke & $4(4)$ & $2(6)$ & 0.598 \\
$\quad$ Non-lethal myocardial infarction & - & - & - \\
Secondary end-point events, $\mathrm{n}(\%)$ & & & 0.613 \\
Total & $13(12)$ & $3(9)$ & 0.735 \\
Grade-IV heart failure & $4(4)$ & $1(3)$ & 0.378 \\
Revascularization & $9(8)$ & & \\
\hline
\end{tabular}

O-AP, oral anti-platelet.

Effect of standardized administration of dual anti-platelet agents on the end-points. Age, gender, hypertension, diabetes, smoking, standardized administration of dual anti-platelet agents, standardized administration of statins, standardized administration of beta receptor antagonists and standardized administration of ACEI/ARB were used as co-variants in the
Cox regression analysis, which revealed that standardized administration of dual anti-platelet agents significantly reduced the incidence rate of primary end-point events (HR=0.307; 95\% CI: 0.099-0.953; $\mathrm{P}=0.041$ ), including all-cause mortality (HR=0.162; 95\% CI: 0.029-0.890; $\mathrm{P}=0.036$ ) (Table III). The Kaplan-Meier curves also indicated that in patients who 
Table III. Cox regression analysis of standardized administration of dual anti-platelet agents for end-points events.

\begin{tabular}{lccc}
\hline Event & HR value & 95\% CI & \\
\hline Primary end-point events, n (\%) & & $0.099-0.953$ & 0.041 \\
Total & 0.307 & $0.029-0.890$ & 0.036 \\
All-cause mortality & 0.162 & $0.125-3.740$ & 0.662 \\
Non-lethal stroke & 0.685 & - & - \\
Non-lethal myocardial infarction & - & $0.298-2.350$ \\
Secondary end-point events, n (\%) & & $0.911-1.075$ \\
Total & 0.836 & $0.469-28.162$ & 0.735 \\
Grade-IV heart failure & 0.990 & 0.812 \\
Revascularization & 3.633 & 0.217 \\
\hline
\end{tabular}

HR, hazard ratio; CI, confidence interval.

A

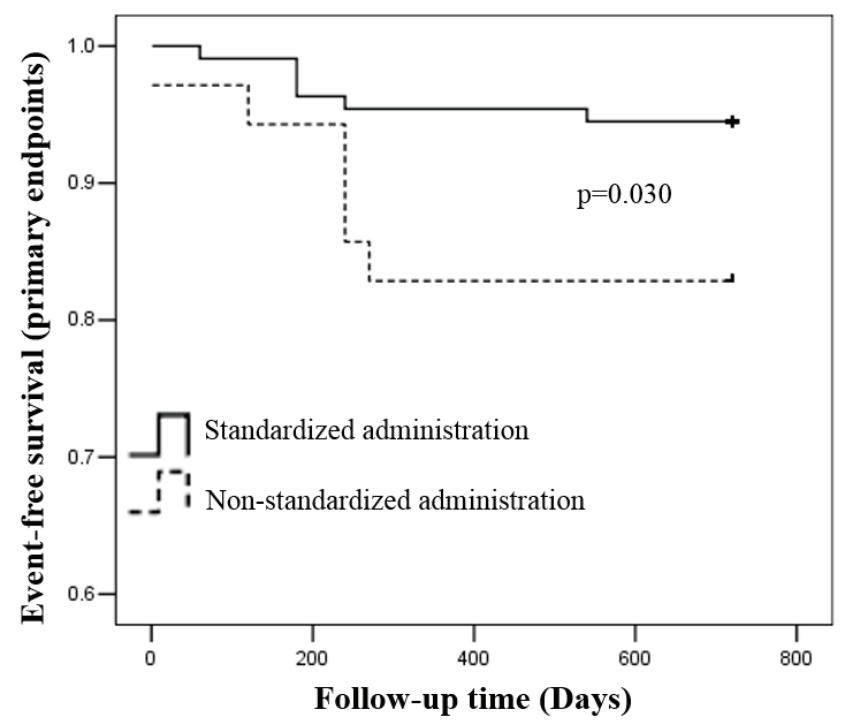

B



Figure 1. Kaplan-Meier curves of (A) primary endpoint event-free survival and (B) all-cause mortality event-free survival associated with standardized and non-standardized anti-platelet administration.

received standardized administration of dual anti-platelet agents, the risk of primary end-point events $(\mathrm{P}=0.030)$ and all-cause mortality $(\mathrm{P}=0.001)$ was significantly decreased (Fig. 1).

\section{Discussion}

In the present study, $76 \%$ of the patients with coronary heart disease regularly took standard anti-platelet medication; furthermore, $80 \%$ received dual anti-platelet drug therapy in 70 out of 144 patients who received PCI therapy. Furthermore, the incidence rate of primary end-point events was low in patients with standardized administration of anti-platelet drugs compared to that in those without standardized administration. In addition, Kaplan-Meier curves and Cox regression analysis showed that standardized administration of anti-platelet drugs markedly reduced the incidence of primary end-point events; further analysis showed that only all-cause mortality was significantly reduced.
Activation and aggravation of platelets has a critical role in coronary plaque rupture and thrombosis. Anti-platelet therapy with drugs such as aspirin and clopidogrel provides a benefit for patients with coronary heart disease. According to the European Society of Cardiology guidelines $(12,14)$, patients with coronary heart disease require treatment with aspirin and patients with ACS after PCI should be treated with aspirin and clopidogrel for at least 12 months if no contraindications are present. Aspirin is the most common anti-platelet drug used in clinical practice and numerous large-scale, randomized and controlled studies have confirmed that the benefits outweigh the risks. A meta-analysis showed that daily oral aspirin $(75-150 \mathrm{mg}$ ) leads to a decrease in cardiac events by $33 \%$ in patients with steady coronary heart disease and by $53 \%$ in patients after PCI (15). Clopidogrel blocks the ADP receptor on the platelet membrane so as to inhibit platelet aggregation. The CURE trial (16), the CURRENT-OASIS study (17) and the TYCOON study (6) demonstrated that combined clopidogrel and aspirin 
significantly reduces the incidence rate of major adverse cardiac events in patients with coronary heart disease with after PCI.

The importance of anti-platelet drugs use has been recognized by numerous physicians, while numerous patients in China still do not receive standardized management, particularly in basic hospitals. A total of 144 patients with coronary heart disease were enrolled in the present follow-up study and the results showed that the ratio of patients who received standardized administration of anti-platelet therapy was only $76 \%$. Furthermore, $80 \%$ of patients underwent dual anti-platelet therapy in 70 cases with PCI therapy.

Premature discontinuation of dual anti-platelet therapy was a predictive factor of ST after PCI and increased the risk of major adverse cardiac events $(18,19)$. Rossini et al $(20)$ performed a 3-year follow-up study and found that patients with early discontinuation of anti-platelet agents within the first 12 months experienced a greater incidence of major adverse cardiac events (28.6 vs. $13.7 \%$; $\mathrm{P}<0.01)$ and $\mathrm{ST}(7.6$ vs. $3.4 \%$; $\mathrm{P}=0.038)$. Eisenstein et al (21) performed a 2-year follow-up study and showed that the risk of mortality and incidence of myocardial infarction was obviously increased in patients treated with anti-platelet agents for $<12$ months. A retrospective study showed that the ST rate of patients with the first-generation drug-eluting stent who discontinued clopidogrel within the first year was obviously increased, whereas no definite ST events occurred in the cohort with the second-generation drug-eluting stent (22). Furthermore, the rates of mortality and major adverse cardiac events were increased in the firstas well as in the second-generation drug-eluting stent cohort. Therefore, standardized administration of anti-platelet agents is important for improving the prognosis and reducing the incidence of adverse cardiac events in patients with coronary heart disease. However, numerous studies have shown that compliance of anti-platelet therapy was low, particularly for the dual anti-platelet therapy. The PARIS study assessed 5,018 PCI patients, of which $49.2 \%$ discontinued dual anti-platelet therapy within 1 year (23). The APTOR trial, which assessed 4,184 ACS patients from 14 European countries, revealed that only $43 \%$ received optimal secondary prevention therapy after PCI and a diet or exercise, and after 1 year, the percentage of patients taking dual anti-platelet medication was $99 \%$ in the optimal cohort and $49 \%$ in non-optimal cohort (24). In addition, a survey on of 3,080 Taiwanese ACS patients showed that use of dual anti-platelet therapy fell from $74.8 \%$ at discharge to $24.9 \%$ at 1-year follow-up (25).

In conclusion, the present study revealed that standardized administration of anti-platelet agents markedly reduced primary end-point events in patients with coronary heart disease. Further analysis demonstrated that all-cause mortality was significantly reduced. However, there was low compliance. Therefore, in future clinical practice, communication between physicians and patients should be enhanced and patient management should be focused on in order to enhance the benefit of patients from standardized dual anti-platelet therapy.

\section{Acknowledgements}

The present study was supported by the Key Science and Technology program of Anhui Province (grant no. 09010302083).

\section{References}

1. Yang G, Wang Y, Zeng Y, Gao GF, Liang X, Zhou M, Wan X, Yu S, Jiang Y, Naghavi M, et al: Rapid health transition in China, 1990-2010: Findings from the global Burden of disease study 2010. Lancet 381: 1987-2015, 2013.

2. Seimiya K, Inami S, Takano M, Ohba T, Sakai S, Takano T and Mizuno K: Significance of plaque disruption sites in acute coronary syndrome. J Nippon Med Sch 73: 141-148, 2006.

3. Patrono C, Andreotti F, Arnesen H, Badimon L, Baigent C, Collet JP, De Caterina R, Gulba D, Huber K, Husted S, et al: Antiplatelet agents for the treatment and prevention of atherothrombosis. Eur Heart J 32: 2922-2932, 2011.

4. Ong AT, Hoye A, Aoki J, van Mieghem CA, Rodriguez Granillo GA, Sonnenschein K, Regar E, McFadden EP, Sianos G, van der Giessen WJ, et al: Thirty-day incidence and six-month clinical outcome of thrombotic stent occlusion after bare-metal, sirolimus, or paclitaxel stent implantation. J Am Coll Cardiol 45: 947-953, 2005.

5. Iakovou I, Schmidt T, Bonizzoni E, Ge L, Sangiorgi GM, Stankovic G, Airoldi F, Chieffo A, Montorfano M, Carlino M, et al: Incidence, predictors, and outcome of thrombosis after successful implantation of drug-eluting stents. JAMA 293: 2126-2130, 2005.

6. Di Sciascio G, Patti G, Pasceri V, Colonna G, Mangiacapra F and Montinaro A; ARMYDA-4 RELOAD Investigators: Clopidogrel reloading in patients undergoing percutaneous coronary intervention on chronic clopidogrel therapy: Results of the ARMYDA-4 RELOAD (Antiplatelet therapy for Reduction of MYocardial Damage during Angioplasty) randomized trial. Eur Heart J 31: 1337-1343, 2010.

7. Patti G,Pasceri V, Mangiacapra F,Colonna G, Vizzi V, Ricottini E, Montinaro A, D'Ambrosio A, Wijns W, Barbato E, et al: Efficacy of clopidogrel reloading in patients with acute coronary syndrome undergoing percutaneous coronary intervention during chronic clopidogrel therapy (from the Antiplatelet therapy for Reduction of MYocardial Damage during Angioplasty [ARMYDA-8 RELOAD-ACS] trial). Am J Cardiol 112: 162-168, 2013.

8. Fox KA, Mehta SR, Peters R, Zhao F, Lakkis N, Gersh BJ and Yusuf S; Clopidogrel in Unstable angina to prevent Recurrent ischemic Events Trial: Benefits and risks of the combination of clopidogrel and aspirin in patients undergoing surgical revascularization for non-ST-elevation acute coronary syndrome: The Clopidogrel in unstable angina to prevent recurrent ischemic events (CURE) trial. Circulation 110: 1202-1208, 2004.

9. Brener SJ, Steinhubl SR, Berger PB, Brennan DM and Topol EJ; CREDO Investigators: Prolonged dual antiplatelet therapy after percutaneous coronary intervention reduces ischemic events without affecting the need for repeat revascularization: Insights from the CREDO trial. J Invasive Cardiol 19: 287-290, 2007.

10. Pilgrim T and Windecker S: Antiplatelet therapy for secondary prevention of coronary artery disease. Heart 100: 1750-1756, 2014.

11. Qiao S, Chen L, Chen S, Wang W and Zhu G: One-year outcomes from an all-comers chinese population of patients implanted with the resolute zotarolimus-eluting stent. Am J Cardiol 113: 613-620, 2014.

12. Chinese Society of Cardiology of Chinese Medical Association; Editorial Board of Chinese Journal of Cardiology: Expert consensus of antiplatelet therapy in cardiovascular disease. Zhonghua Xin Xue Guan Bing Za Zhi 41: 183-194, 2013 (In Chinese).

13. Madsen BK, Hansen JF, Stokholm KH, Brøns J, Husum D and Mortensen LS: Chronic congestive heart failure. Description and survival of 190 consecutive patients with a diagnosis of chronic congestive heart failure based on clinical signs and symptoms. Eur Heart J 15: 303-310, 1994.

14. Smith SC Jr, Allen J, Blair SN, Bonow RO, Brass LM, Fonarow GC, Grundy SM, Hiratzka L, Jones D, Krumholz HM, et al: AHA/ACC guidelines for secondary prevention for patients with coronary and other atherosclerotic vascular disease: 2006 update: Endorsed by the national heart, lung, and blood institute. Circulation 113: 2363-2372, 2006.

15. Antithrombotic Trialists' (ATT) Collaboration, Baigent C, Blackwell L, Collins R, Emberson J, Godwin J, Peto R, Buring J, Hennekens C, Kearney P, et al: Aspirin in the primary and secondary prevention of vascular disease: Collaborative meta-analysis of individual participant data from randomised trials. Lancet 373: 1849-1860, 2009. 
16. Mehta SR, Yusuf S, Peters RJ, Bertrand ME, Lewis BS, Natarajan MK, Malmberg K, Rupprecht $H$, Zhao F, Chrolavicius S, et al: Effects of pretreatment with clopidogrel and aspirin followed by long-term therapy in patients undergoing percutaneous coronary intervention: The PCI-CURE study. Lancet 358: 527-533, 2001.

17. CURRENT-OASIS 7 Investigators, Mehta SR, Bassand JP, Chrolavicius S, Diaz R, Eikelboom JW, Fox KA, Granger CB, Jolly S, Joyner CD, et al: Dose comparisons of clopidogrel and aspirin in acute coronary syndromes. N Engl J Med 363: 930-942, 2010.

18. Dangas GD, Claessen BE, Mehran R, Xu K and Stone GW: Stent thrombosis after primary angioplasty for STEMI in relation to non-adherence to dual antiplatelet therapy over time: Results of the HORIZONS-AMI trial. EuroIntervention 8: 1033-1039, 2013.

19. Valgimigli M, Campo G, Monti M, Vranckx P, Percoco G Tumscitz C, Castriota F, Colombo F, Tebaldi M, Fucà G, et al: Short- versus long-term duration of dual-antiplatelet therapy after coronary stenting: A randomized multicenter trial. Circulation 125: 2015-2026, 2012.

20. Rossini R, Capodanno D, Lettieri C, Musumeci G, Nijaradze T, Romano M, Lortkipanidze N, Cicorella N, Biondi Zoccai G, Sirbu V, et al: Prevalence, predictors, and long-term prognosis of premature discontinuation of oral antiplatelet therapy after drug eluting stent implantation. Am J Cardiol 107: 186-194, 2011.
21. Eisenstein EL, Anstrom KJ, Kong DF, Shaw LK, Tuttle RH, Mark DB, Kramer JM, Harrington RA, Matchar DB, Kandzari DE, et al: Clopidogrel use and long-term clinical outcomes after drug-eluting stent implantation. JAMA 297: 159-168, 2007.

22. Loh JP, Torguson R, Pendyala LK, Omar A, Chen F, Satler LF, Pichard AD and Waksman R: Impact of early versus late clopidogrel discontinuation on stent thrombosis following percutaneous coronary intervention with first- and second-generation drug-eluting stents. Am J Cardiol 113: 1968-1976, 2014.

23. Mehran R, Baber U, Steg PG, Ariti C, Weisz G, Witzenbichler B, Henry TD, Kini AS, Stuckey T, Cohen DJ, et al: Cessation of dual antiplatelet treatment and cardiac events after percutaneous coronary intervention (PARIS): 2 year results from a prospective observational study. Lancet 382: 1714-1722, 2013.

24. Zeymer U, Berkenboom G, Coufal Z, Belger M, Sartral M, Norrbacka K and Bakhai A; APTOR investigators: Predictors, cost, and outcomes of patients with acute coronary syndrome who receive optimal secondary prevention therapy: Results from the antiplatelet treatment observational registries (APTOR). Int J Cardiol 170: 239-245, 2013.

25. Chiang FT, Shyu KG, Wu CJ, Mar GY, Hou CJ, Li AH, Wen MS, Lai WT, Lin SJ, Kuo CT, et al: Predictors of 1-year outcomes in the Taiwan acute coronary syndrome full spectrum registry. J Formos Med Assoc 113: 794-802, 2014 